\title{
Les peptides du lait à activités physiologiques I. Facteurs de croissance dans le lait et le lactosérum
}

\author{
P Nabet ${ }^{1}$, F Belleville-Nabet ${ }^{1}$, G Linden ${ }^{2}$ \\ 1 Faculté de Médecine de Nancy, laboratoire de biochimie médicale, \\ BP 184, 54505 Vandceuvre-lès-Nancy, Cedex \\ 2 Faculté des Sciences, laboratoire associé à I'INRA de biochimie appliquée, \\ boulevard des Aiguillettes, 54500 Vandœuvre-lès-Nancy, France
}

peptide / activité physiologique / facteur de croissance / lactosérum

Milk peptides with physiological activities. I. Growth factors in milk and whey.

peptide / physiological activity / growth factor / lactoserum

\section{INTRODUCTION}

Je voudrais remercier les organisateurs de cette réunion et le Professeur G Linden de me permettre de présenter nos travaux communs sur les facteurs de croissance du lait. Le Professeur Linden n'est plus à présenter dans cette assemblée : il y est chez lui. Vous n'avez pas l'habitude de me voir et je présenterai brièvement le laboratoire que je dirige : il s'agit d'un laboratoire hospitalouniversitaire et la partie hospitalière n'est pas moins importante que la partie universitaire car elle nous offre une très large gamme de moyens analytiques pour doser et caractériser nos produits (milieux de culture, fractions de purification, etc). D'un point de vue universitaire, étant par- tis de l'hormone de croissance, nous en sommes venus tout naturellement aux peptides à activités facteurs de croissance (dont les IGF-I et IGF-II) et, en particulier, à certains de faible poids moléculaire, qui agissent en synergie avec d'autres facteurs de croissance et que nous avons mis en évidence de façon originale dans le sang.

Afin de suivre des étapes de purification, nous avons été amenés à mettre sur pied tout un secteur de culture de cellules d'eucaryotes supérieurs avec toutes les techniques que nous exposerons dans un instant.

Collaborant, depuis de nombreuses années avec l'équipe du Professeur Linden, il était normal que nous nous intéressions aux facteurs de croissance du lait, appor-

\footnotetext{
* Correspondence et tirés à part
} 
tant, dans cette entreprise commune, une vision plus physiologique des choses.

\section{NOTION DE FACTEURS DE CROIS- SANCE. FACTEURS DE CROISSANCE ET LAIT. ACTIVITÉS BIOLOGIQUES}

Qu'est-ce qu'un facteur de croissance? La réponse n'est pas évidente pour 3 raisons principales:

- de nombreux facteurs sont impliqués dans la croissance cellulaire, par exemple : hormones thyroïdiennes, transferrine, oligoéléments, etc, qui ne sont pas classés parmi les facteurs de croissance,

- l'augmentation quotidienne du nombre de facteurs de croissance connus fournit une vision de plus en plus compliquée et variée,

- le phénomène même de croissance cellulaire n'est pas univoque. La biomasse peut augmenter, soit par augmentation de taille des cellules (et certains facteurs agissent pour favoriser ce phénomène), soit par division cellulaire (et d'autres facteurs déclenchent cette division).

On peut cependant proposer une définition: on classe dans le groupe des facteurs de croissance, des composés de nature peptidique, de poids moléculaire situé entre 3000 et 20000 (pour les plus hauts $\mathrm{PM}$, il s'agit de polymères), se fixant sur des récepteurs spécifiques des membranes plasmiques cellulaires, puis internalisés, et qui induisent ou initient la croissance cellulaire, en agissant par contiguité de façon paracrine ou autocrine (fig 1). La liaison au récepteur déclenche une cascade de réactions intracellulaires qui transmettent le message jusqu'au noyau par l'une des 3 voies suivantes :

- activation directe ou indirecte des canaux ioniques,
- activation de la tyrosine kinase du récepteur,

- activation de $G$ protéines et des phospholipases $\mathrm{C}$ et $\mathrm{A}_{2}$ (fig 2).

Le tableau I résume les principaux facteurs de croissance connus actuellement dans le sang ou les liquides biologiques et chaque jour apporte son lot de nouveaux facteurs. Pour ce qui concerne le lait, nombre de ces facteurs s'y retrouvent (Read, 1989), comme entre autres les IGF (Juskevich et Guyer, 1990), le PDGF et le FGF ou la bombésine. II est probable que leur présence joue un rôle important chez le nouveau-né, soit comme facteurs de croissance de l'organisme entier, soit plus probablement dans la différenciation de la muqueuse du tractus digestif. Ces facteurs

TISSU PRODUCTEUR

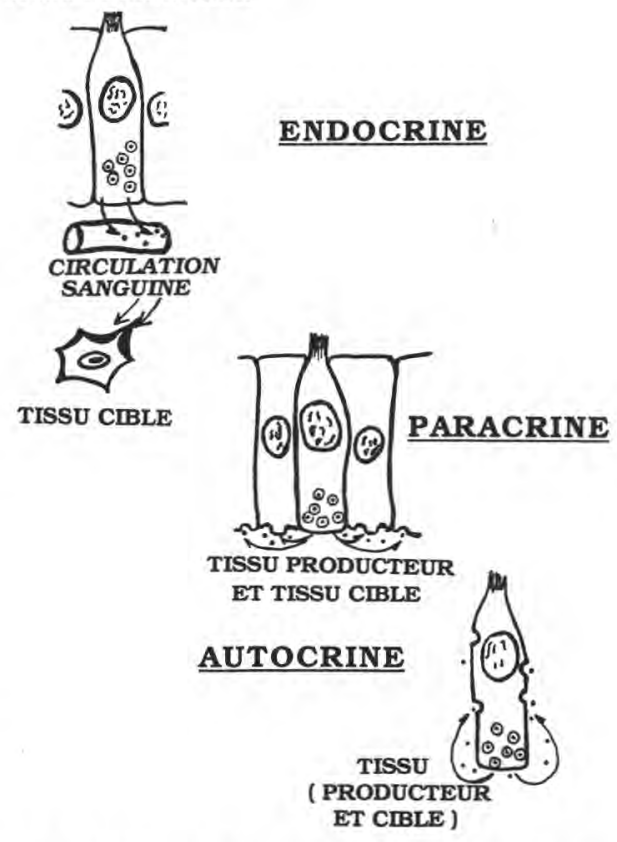

Fig 1. Modes de transmission du message chimique.

The chemical message: modes of transmission. 
sont, en général, à forte concentration dans le colostrum et leur taux diminue très vite au cours des premières $h$ ou des premiers j de lactation.

Les techniques de cultures de cellules eucaryotes permettent de mesurer les activités biologiques de ces facteurs et on utilise 3 types de tests :
- des tests à court terme qui, généralement, consistent à mesurer l'incorporation d'un précurseur marqué dans des macromolécules $\left({ }^{3} \mathrm{H}\right.$ thymidine dans I'ADN, ${ }^{3} \mathrm{H}$ amino-acides dans les protéines, $35 \mathrm{SO}_{4}{ }^{2-}$ dans les glycoaminoglycannes, etc),

- des tests à moyen terme consistant à suivre la prolifération cellulaire (comptage

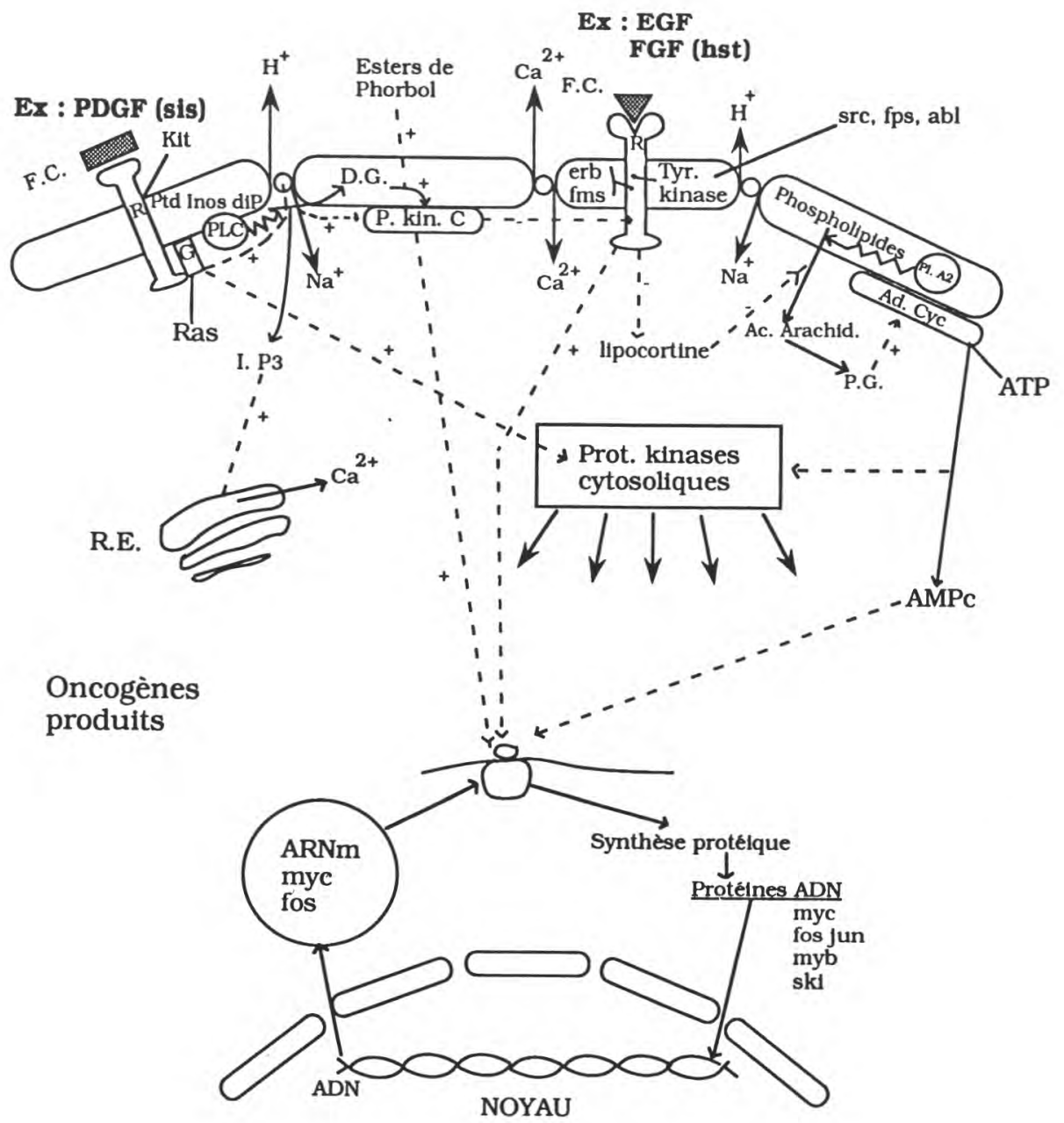

Fig 2. Principaux mécanismes d'action des facteurs de croissance.

Growth factors : main mechanisms of action. 
Tableau I. Principaux facteurs de croissance contenus dans divers tissus ou liquides biologiques. Main growth factors found in various tissues and biological fluids.

\begin{tabular}{|c|c|c|c|}
\hline Facteur de croissance & Sources & Tissus cibles & moléc kDa \\
\hline $\begin{array}{l}\text { Bombésine et peptides } \\
\text { apparentés }\end{array}$ & Plusieurs tissus & Tous les tissus & $1-3$ \\
\hline Bone derived GF & os, cartilage & Chondrocytes & $6-8$ \\
\hline Colony stimulating factor & $\begin{array}{l}\text { Lymphocytes, GB, } \\
\text { urines }\end{array}$ & $\begin{array}{l}\text { Granulocytes, } \\
\text { macrophages }\end{array}$ & $40-70$ \\
\hline Endothelial GF & Hypothalamus & Cell endothéliales & $17-25$ \\
\hline Epidermal GF & $\begin{array}{l}\text { Glandes sous maxill } \\
\text { urines }\end{array}$ & $\begin{array}{l}\text { Cell épidermales } \\
\text { fibroblastes }\end{array}$ & 6 \\
\hline Erythropoiétine & Rein, plasma & Précurseurs GR & $27-62$ \\
\hline Fibroblast derived GF & Fibroblastes transform & Fibroblastes & 31 \\
\hline Fibroblast GF & $\begin{array}{l}\text { Hypophyse bovine, } \\
\text { cerveau }\end{array}$ & $\begin{array}{l}\text { Cell } \\
\text { mésodermiques }\end{array}$ & 16 \\
\hline $\begin{array}{l}\text { Insuline } \\
\text { Insuline-like GF I } \\
\text { IGF I/Som C }\end{array}$ & $\begin{array}{l}\text { Pancréas } \\
\text { Foie, sang }\end{array}$ & $\begin{array}{l}\text { Toutes cellules } \\
\text { Toutes cellules adultes }\end{array}$ & $\begin{array}{l}6 \\
7,5\end{array}$ \\
\hline IGF II/MSA & Foie, sang & Toutes cellules du fœtus & 7,5 \\
\hline $\begin{array}{l}\text { Les interleukines } \\
1 \rightarrow 6\end{array}$ & $\begin{array}{l}\text { GB, macrophages } \\
\text { cell épithéliales }\end{array}$ & $\begin{array}{l}\text { GB, lymphocytes } \\
\text { B et T }\end{array}$ & $5-25$ \\
\hline $\begin{array}{l}\text { Nerve GF } \\
\text { Nerve NGF }\end{array}$ & Glande sous maxill & $\begin{array}{l}\text { Neurones, cell } \\
\text { gliales }\end{array}$ & 13 \\
\hline PDGF & Plaquettes sanguines & Fibroblastes, cell muscle & 30 \\
\hline $\begin{array}{l}\text { Transforming GF } \\
\alpha, \beta \text { et } \gamma \text { (TGF) }\end{array}$ & Plusieurs tissus & $\begin{array}{l}\text { Fibroblastes, cell } \\
\text { épithéliales }\end{array}$ & $5-6$ \\
\hline $\begin{array}{l}\text { Tumor necrosing } \mathrm{F} \\
\text { TNF, } \alpha, \beta\end{array}$ & Plusieurs tissus & Angiogenèse & 15 \\
\hline Thrombine & Foie, plasma & Fibroblastes & 30 \\
\hline
\end{tabular}

GB : globules blancs; GR : globules rouges; GB : white corpuscles; GR : red corpuscles. 
cellulaire) pendant 4-12 j. II est fréquent d'observer que les cellules poussent bien au début et ensuite elles périclitent, comme si elles épuisaient un facteur en réserve dans les cellules elles-mêmes,

- des tests à long terme, plusieurs semaines à plusieurs mois, en réacteur, permettant de mesurer les métabolismes et les productions des cellules cultivées.

Les 3 types de techniques devront être utilisés pour définir l'activité d'un composé donné. De même qu'il est nécessaire d'utiliser plusieurs souches cellulaires : pour notre part, nous travaillons habituellement sur des fibroblastes (soit lignées continues, soit cellules de premières implantations comme des fibroblastes de peau humaine ou des fibroblastes d'embryon de poulet), des hybridomes ou des myélomes, des cellules épithéliales (figs 3-7).

Ces tests in vitro peuvent être complétés, le cas échéant, par des tests in vivo concernant l'activation de la cicatrisation chez l'animal (ou chez l'homme, mais de façon plus rare et plus délicate compte tenu des contraintes légales).

\section{PRÉSENTATION DE NOS RÉSULTATS SUR LE LACTOSÉRUM}

Dès 1978, Klagsburn, travaillant sur le lait humain, avait montré que des fractions de ce lait pouvaient activer la biosynthèse de I'ADN dans des cellules en culture. Nous avions repris ces travaux en les confirmant, tant sur le lait (bovin) entier frais, que sur le lait thermisé.

Le problème que nous avons alors posé était de savoir si le lactosérum, en provenance de l'industrie fromagère, contenait aussi les facteurs suffisants pour permettre la croissance cellulaire à court, moyen et long terme (Damerdji et al, 1988).

La figure 8 montre un des essais réalisés à partir de lactosérums, provenant de

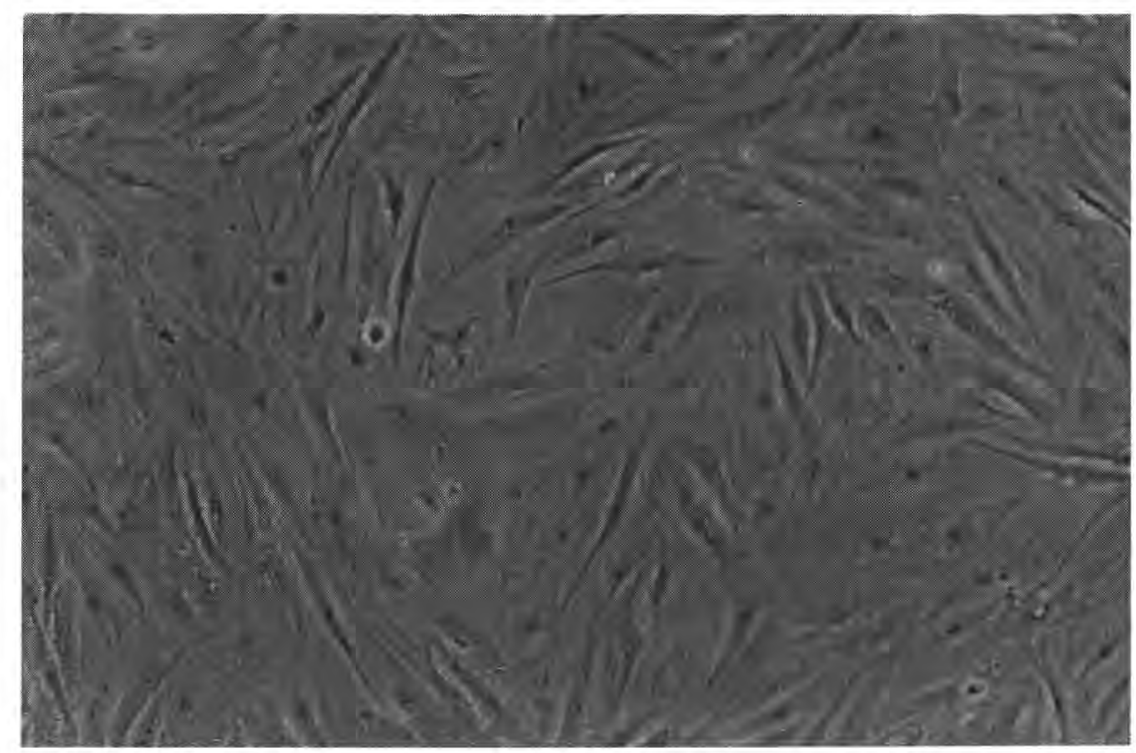

Fig 3. Fibroblastes de poumons.

Lung fibroblasts. 


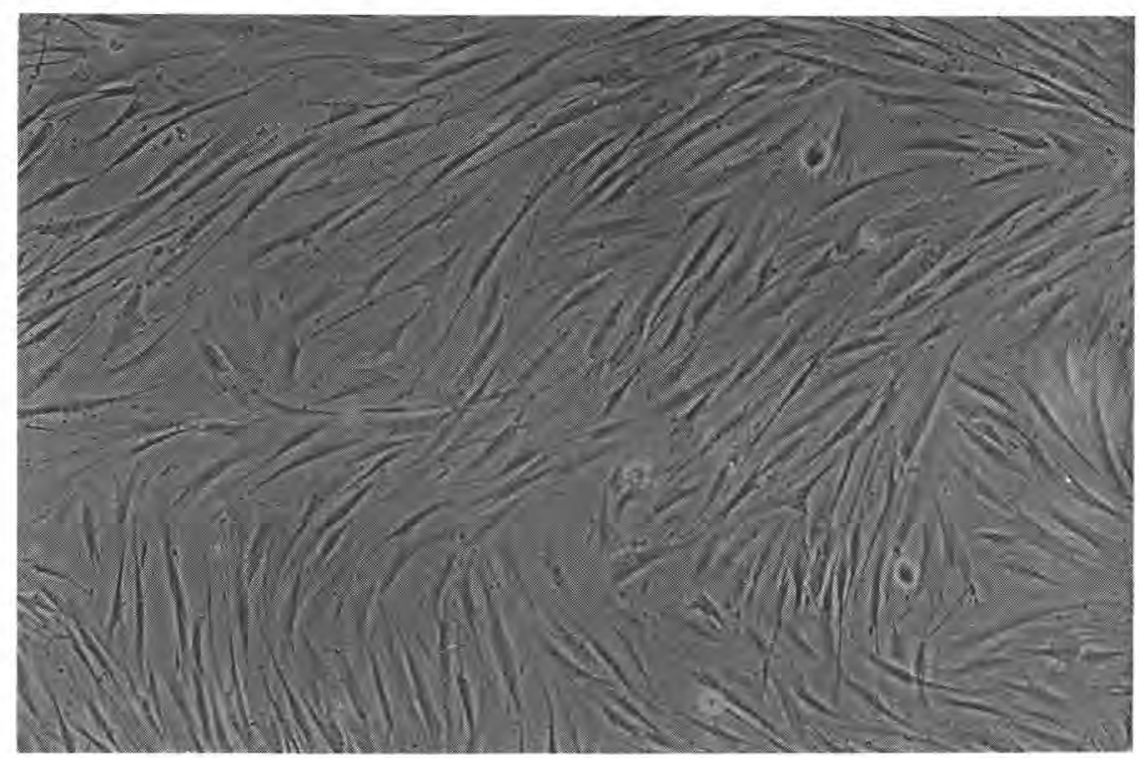

Fig 4. Fibroblastes de peau.

Skin fibroblasts.

'industrie laitière, doux ou acide, ultrafiltrés ou non, thermisés ou non (il s'agit là d'un test à court terme). II apparaît nettement que 2 fractions sont aussi actives que le sérum de veau fœtal : elles ont, pour caractéristiques, d'être débarrassées par ultrafiltration des molécules de poids moléculaire inférieur à 10000 et d'être thermisées plusieurs fois au cours de la préparation. Comme si, au cours de ces manipulations, d'une part on éliminait des composés inhibiteurs présents dans le lactosérum et qu'on activait par la thermisation d'autres composés.

À ce niveau, il faut préciser que notre expérience prouve que si un produit est peu actif dans un test à court terme, il ne se révèle jamais actif à moyen et long terme. Par contre, tout produit actif à court terme n'est pas obligatoirement actif à moyen et long terme.
La figure 9 montre, en effet, que ces fractions de lactosérum permettent la croissance d'hybridomes pendant quelques jours, mais si l'on veut cultiver à long terme, il faut obligatoirement additionner ces fractions d'au moins $0,5 \%$ de sérum de veau fœtal (SVF) et de façon optimale de $1 \%$ de SVF. Bien entendu, nous avons vérifié que $1 \%$ de SVF à lui seul ne pouvait pas soutenir la croissance cellulaire à long terme. Le lactosérum contient bien des composés qui stimulent la croissance cellulaire, mais nécessite encore un ou plusieurs composés apportés en faible quantité par le SVF pour être actif à long terme.

La sécrétion d'immunoglobulines, par ces hybridomes, est absolument la même en SVF et en lactosérum.

Tous les lactosérums liquides ou en poudre du commerce, que nous avons testés, sont actifs. Cependant, les plus actifs 


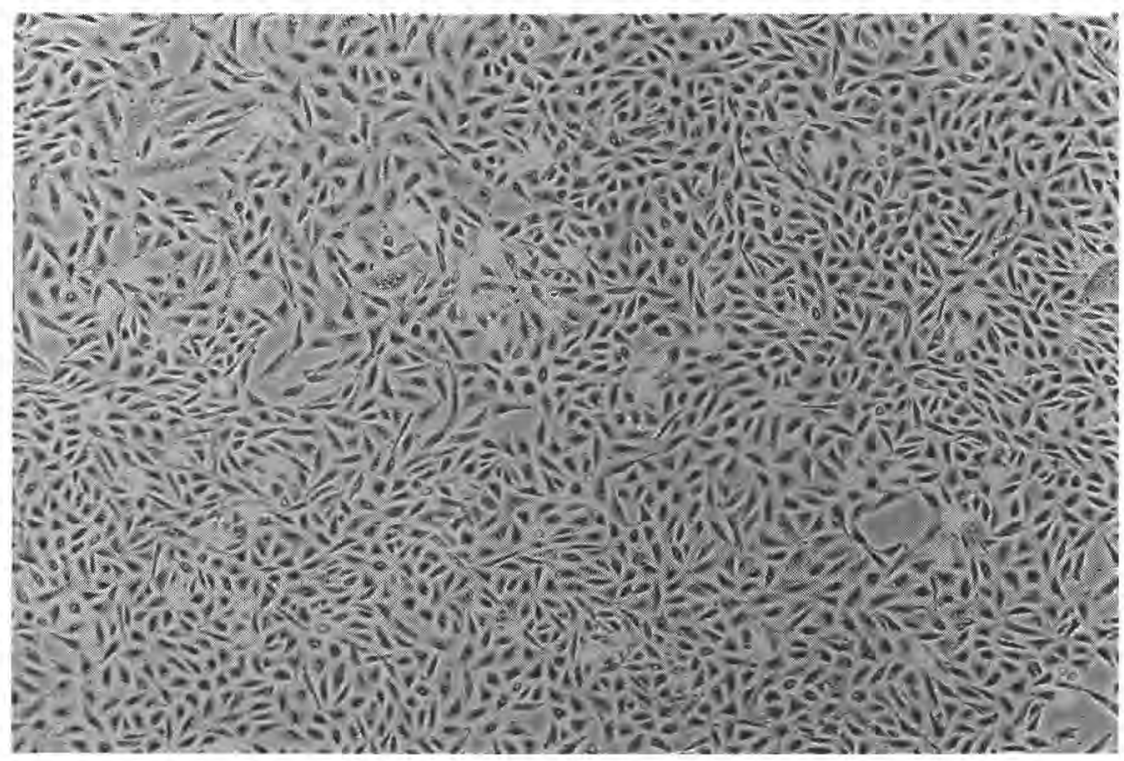

Fig 5. $\mathrm{CHO}$ en boîte.

$\mathrm{CHO}$ cells in flaskes.

restent les lactosérums doux qui n'ont pas fait l'objet de manipulations ultérieures comme, par exemple, des ultrafiltrations multiples ou une opération de séchage. La thermisation augmente l'activité mitogénique du lactosérum, de même que l'élimination de petites molécules (dont le lactose probablement).

Afin de mieux cerner les principes actifs, nous avons effectué un certain nombre de dosages outre les dosages radio-immunologiques des facteurs de croissance connus (Derouiche et al, 1990). Le tableau II résume les résultats des analyses effectuées:

- on retrouve des lipides solubles en quantités non négligeables dont des acides gras insaturés, du cholestérol, des triglycérides,
- on y retrouve des hormones comme I'ACTH, la progestérone, l'insuline, etc,

- notre attention a été attirée par la haute teneur en AMP cyclique du lactosérum. Cet AMPc provient manifestement de l'action des micro-organismes, puisqu'il ne préexiste pas dans le lait correspondant; il est probablement lié à une protéine puisqu'il n'est pas éliminé par les ultrafiltrations et il est très spécifiquement consommé par les cellules en culture comme le montre la figure 10. Ceci laisse penser qu'il 'se trouve dans le lactosérum sous forme immédiatement assimilable par la cellule, car on sait que I'AMPc moléculaire seul ne passe pas la membrane cellulaire.

Un milieu de culture doit permettre, non seulement la prolifération cellulaire, mais également la conservation des cellules au 
Tableau II. Composition biochimique de deux fractions de lactosérum testées en culture cellulaire. Biochemical composition of 2 whey fractions assayed in cell culture.

\begin{tabular}{|c|c|c|}
\hline & LB S37 & LB S65 \\
\hline $\mathrm{pH}$ & 7,21 & 7,04 \\
\hline Protéines totales $(\mathrm{g} / \mathrm{l})$ & 11 & 42 \\
\hline Glucose (mg/l) & 50 & 90 \\
\hline Galactose $(\mathrm{mg} / \mathrm{l})$ & 5,14 & 4,63 \\
\hline Lactose $(\mathrm{g} / \mathrm{l})$ & 16 & 120 \\
\hline Acides gras totaux $(\mathrm{mg} / \mathrm{l})$ & 615 & 658 \\
\hline Triglycérides (mg/l) & 1410 & 1740 \\
\hline Cholestérol (mg/l) & 60 & 190 \\
\hline Calcium (mg/l) & 207 & 800 \\
\hline Phosphore (mg/l) & 71 & 205 \\
\hline Fer $(\mathrm{mg} / \mathrm{l})$ & 1,58 & 0,49 \\
\hline Sodium (meg/l) & 9 & 19 \\
\hline Potassium (meq/l) & $>10$ & $>10$ \\
\hline Chlorures (meg/l) & 11 & 9 \\
\hline ACTH $(\mathrm{pg} / \mathrm{ml})$ & - & 68 \\
\hline Progestérone (pg/l) & 53 & 100 \\
\hline $\mathrm{AMP}_{\mathrm{C}}(\mathrm{nmol} / \mathrm{l})$ & 592 & 325 \\
\hline $\mathrm{ACE}(\mathrm{ng} / \mathrm{ml})$ & - & - \\
\hline ACTH $(\mathrm{pg} / \mathrm{ml})$ & $<6$ & 68 \\
\hline$\alpha \mathrm{FP}(\mathrm{ng} / \mathrm{ml})$ & $<0,5$ & $<0,5$ \\
\hline $\mathrm{AMP}_{\mathrm{C}}(\mathrm{nmol} / \mathrm{l})$ & 100 & 325 \\
\hline$\beta_{2} M G(m g / l)$ & - & - \\
\hline DHT $(n g / 100 \mathrm{ml})$ & 5 & 4 \\
\hline Cortisol (ng/ml) & - & - \\
\hline Gastrine $(\mathrm{pg} / \mathrm{ml})$ & 15 & 33 \\
\hline Histamine $(\mathrm{nmol} / \mathrm{l})$ & ND & 26 \\
\hline Insuline (mUl/l) & 4 & 4 \\
\hline $\mathrm{LH}(\mathrm{ng} / \mathrm{ml})$ & ND & 0,55 \\
\hline TSH (ng/ml) & ND & - \\
\hline $17 \mathrm{OH} . \mathrm{P}(\mathrm{ng} / 100 \mathrm{ml})$ & 13 & 16 \\
\hline Pep C (nmol/l) & $<100$ & $<100$ \\
\hline Progestérone (pg/ml) & 56 & 100 \\
\hline Prolactine (ng/ml) & ND & 6 \\
\hline $\mathrm{STH}(\mathrm{ng} / \mathrm{ml})$ & - & - \\
\hline Testo (ng/100 ml) & - & - \\
\hline $\mathrm{SM}-\mathrm{C}(\mu \mathrm{mol} / \mathrm{l})$ & - & 3 \\
\hline $\mathrm{Se}^{2-}(\mathrm{mg} / \mathrm{l})$ & - & - \\
\hline $\mathrm{Zn}^{2+}(\mathrm{mg} / \mathrm{l})$ & 0,3 & 0,5 \\
\hline $\mathrm{Cu}^{2+}(\mathrm{mg} / \mathrm{l})$ & - & - \\
\hline $\mathrm{Mg}^{2+}(\mathrm{mg} / \mathrm{l})$ & 96 & 82 \\
\hline
\end{tabular}

- : non détachable; ND : non déterminé; -: not detectable; ND: not determined

froid. Généralement, on conserve ces cellules à $-180^{\circ} \mathrm{C}$ en azote liquide et en milieu riche en SVF (20-30\%). L'équipement nécessaire est très particulier et onéreux, par contre, presque tous les laboratoires sont équipés d'un congélateur mécanique à $-80^{\circ} \mathrm{C}$. Nous avons donc voulu vérifier comment se comportaient les cellules à 
Tableau II. suite

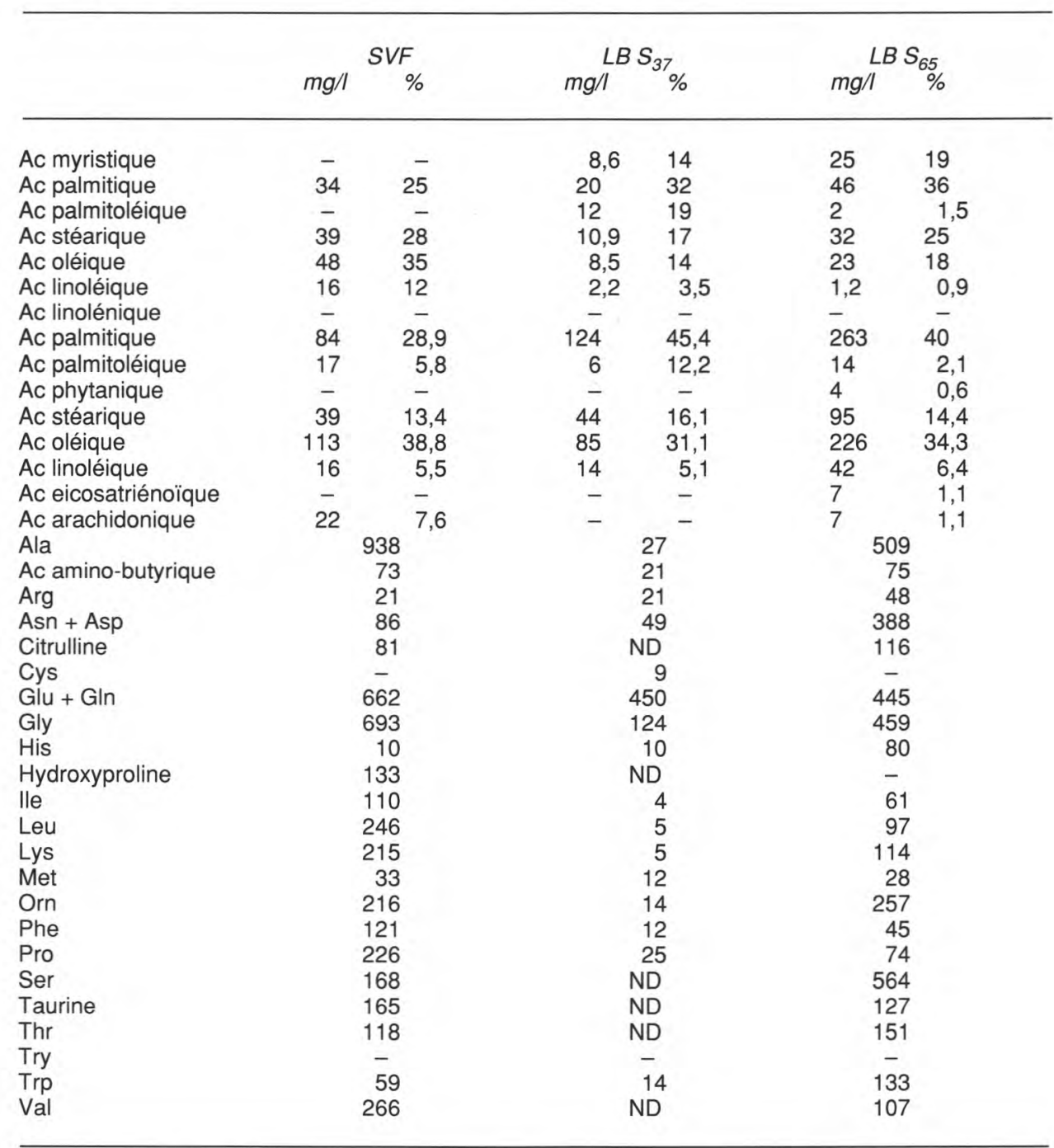

- : Non détectable; ND : Non déterminé; -: not detectable; ND: not determined

cette température et en milieu contenant, soit du SVF à $40 \%$, soit du lactosérum à $40 \%$ (bien entendu, les 2 milieux contenaient $10 \%$ de DMSO et $50 \%$ de milieu de base RPMI).
Le tableau III donne la viabilité cellulaịre à différents temps de conservation dans les 2 cas.

La figure 11 montre bien que, après 2 ans, les cellules conservées en lactosérum 


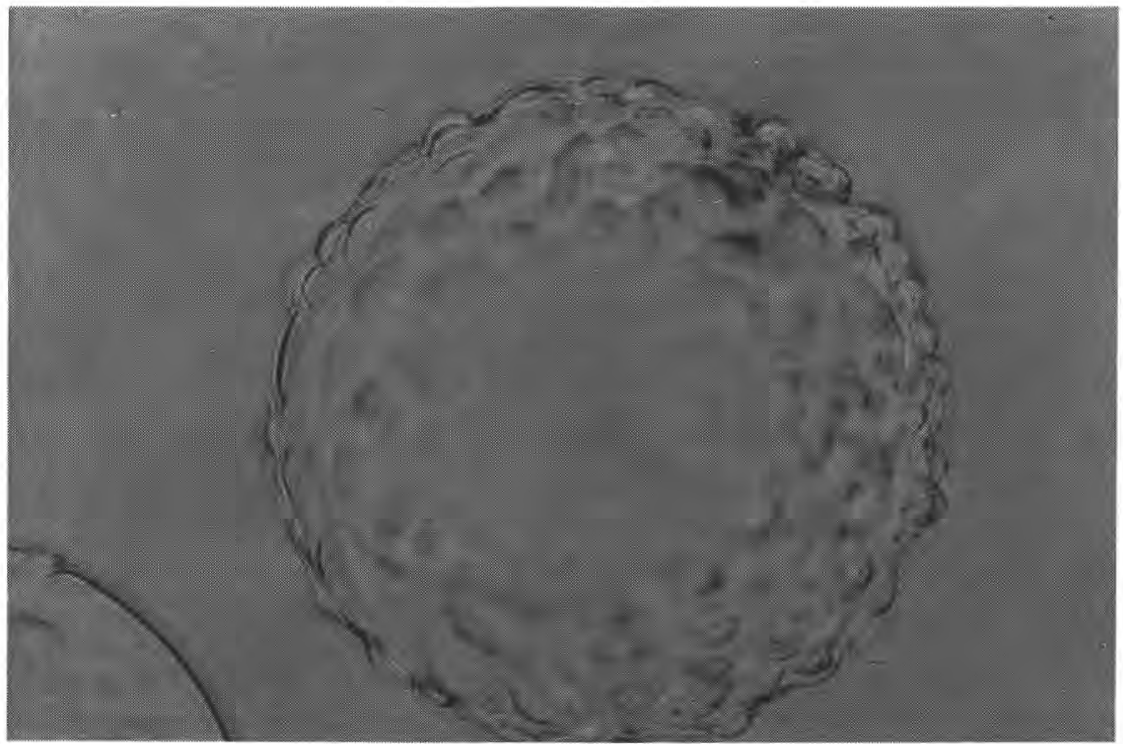

Fig 6. $\mathrm{CHO}$ sur microporteurs.

$\mathrm{CHO}$ cells on microcarrier.

redémarrent leur prolifération lorsqu'on les cultive, tant dans un milieu contenant du lactosérum que dans un milieu contenant du SVF, et qu'elles sécrètent, de façon équivalente, des immunoglobulines (Derouiche et al, 1989). Quant aux cellules conservées en SVF, elles ne redémarrent pas. Ceci est confirmé par la microscopie électronique (fig 12) puisque, en milieu SVF, les cellules sont détériorées, alors qu'en milieu lactosérum, elles restent intactes.

Tableau III. Viabilité d'hybridomes conservés pendant un temps variable, à $-80^{\circ} \mathrm{C}$, soit dans un milieu à base de SVF $(A)$ ou de lactosérum $(B)$.

Cell viability of frozen cells at $-80^{\circ} \mathrm{C}$ in whey or in FCS as a function of time.

\begin{tabular}{|c|c|c|c|}
\hline $\begin{array}{l}\text { Milieu de congélation } \\
\text { Durée de congélation }\end{array}$ & $\begin{array}{l}\text { 10\% DMSO } \\
\text { 40\% SVF } \text { milieu } \\
50 \% \text { RPMI } A\end{array}$ & $\begin{array}{l}10 \% \text { DMSO } \\
40 \% \text { LB S }_{65} \\
50 \% \text { RPMI }\end{array}$ & $\begin{array}{c}\text { milieu } \\
B\end{array}$ \\
\hline $\begin{array}{l}2 \text { mois } \\
6 \text { mois } \\
1 \text { an } \\
2 \text { ans }\end{array}$ & $\begin{array}{l}75 \% \\
61 \% \\
18 \% \\
19 \%\end{array}$ & $\begin{array}{l}90 \% \\
83 \% \\
76 \% \\
78 \%\end{array}$ & \\
\hline
\end{tabular}




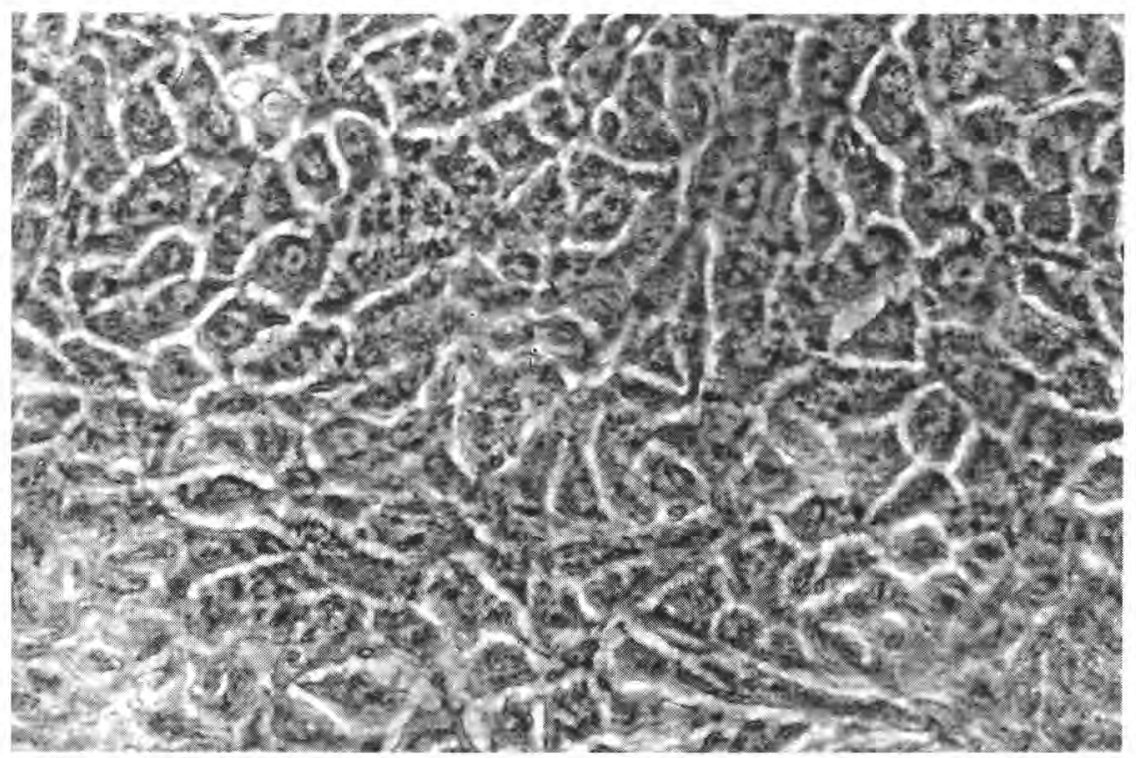

Fig 7. Cellules épithéliales de glandes mammaires bovines.

Epithelial cells from bovine mammary glands.

\section{CONCLUSIONS}

Le lactosérum contient des facteurs permettant la prolifération des cellules eucaryotes d'animaux supérieurs à long terme et aussi des facteurs de préservation et de stabilisation des cellules lors de leur conservation. Nous avons ainsi mis au point un milieu de culture pour lequel un brevet a été obtenu et qui est actuellement commercialisé.

En outre, dans le domaine de la cryoconservation, nous avons montré que les fractions sélectionnées de lactosérum permettent de se passer de l'utilisation de l'azote liquide et conservent les hybridomes à $-80{ }^{\circ} \mathrm{C}$ pendant au moins une durée de 2 ans.

En résumé, la substitution de tout ou partie du SVF présente des avantages, aussi bien d'ordre économique que d'ordre pratique.

\section{REMERCIEMENTS}

Ce travail a pu être réalisé grâce à l'aide financière de l'université de Nancy I, du district de Nancy, de la mission de la recherche de la région Lorraine. 

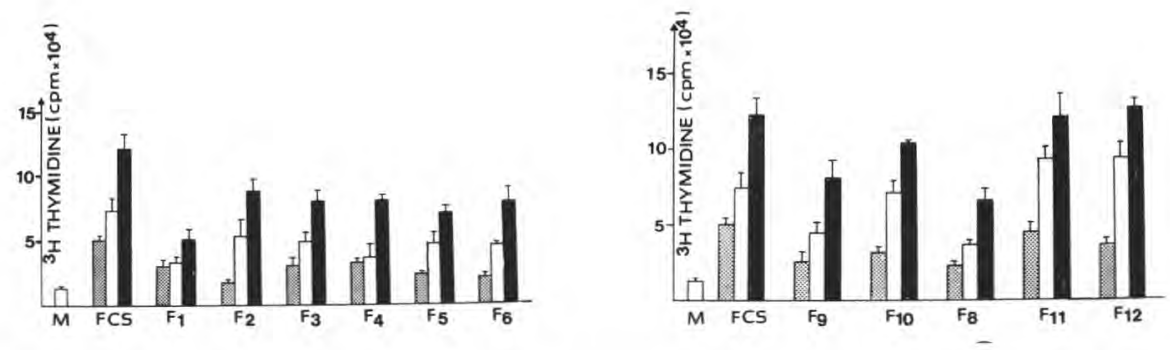

Fig 8. Mesure de l'activité à court terme de différentes fractions de lactosérum. La synthèse d'ADN est mesurée par incorporation de ${ }^{3} \mathrm{H}$ thymidine. M: milieu seul; FCS: sérum de veau fœtal $5 \%, 10 \%$, $20 \% \mathrm{~V} / \mathrm{V} ; \mathrm{F}_{1}$ : lactosérum doux (coagulation par enzyme); $F_{2}$ : lactosérum doux ultrafiltré (seuil de coupure 10000 ) à $15-20^{\circ} \mathrm{C}$ et concentré 6 fois; $F_{3}$ : lactosérum doux ultrafiltré, lavé, concentré 12 fois; $\mathrm{F}_{4}$ : lactosérum acide $\left(\mathrm{HCl}, \mathrm{pH} 4.6,34^{\circ} \mathrm{C}\right) ; \mathrm{F}_{5}$ : lactosérum acide ultrafiltré, concentré 6 fois; $\mathrm{F}_{6}$ : lactosérum acide ultrafiltré, lavé 2 fois, concentré 12 fois; Lait écrémé chauffé 15 à $20 \mathrm{~s}$ à $67^{\circ} \mathrm{C}$, les protéines sont précipitées par enzyme. $F_{7}$ : lactosérum; $F_{8}$ : lactosérum ultrafiltré à $15-20^{\circ} \mathrm{C}$, concentré 6 fois; $F_{9}$ : lactosérum ultrafiltré à $50^{\circ} \mathrm{C}$ et concentré 6 fois; $F_{10}$ : lactosérum ultrafiltré $50^{\circ} \mathrm{C}$, lavé 2 fois, concentré 12 fois; $F_{11}$ : lactosérum chauffé $60 \mathrm{~min}, 65^{\circ} \mathrm{C}$, UF $50^{\circ} \mathrm{C}$, concentré 6 fois; $F_{12}$ : lactosérum chauffé $60 \mathrm{~min}, 65^{\circ} \mathrm{C}$, UF $50^{\circ} \mathrm{C}$, lavage 2 fois, concentré 12 fois.

Measurement at short-term of mitogenic activity of various whey fractions. DNA synthesis was measured by ${ }^{3} \mathrm{H}$ thymidine incorporation. M: medium RPMI 1640 Boehringer. FCS: $5 \%, 10 \%, 20 \%$ VIV: $F_{1}$ : sweet whey; $F_{2}$ : ultrafiltered sweet whey $\left(10000\right.$ d) at $15-20{ }^{\circ} \mathrm{C}$, concentrated 6 times. $F_{3}$ : ultrafiltered sweet whey $(10000 \mathrm{~d})$, washed twice and concentrated 12 times. $F_{4}$ : acidic whey $(\mathrm{HCl}, \mathrm{pH} \mathrm{4.6}$, $34{ }^{\circ} \mathrm{C}$ ), $F_{1}$ : acidic whey treated as $F_{2} ; F_{6}$ : acidic whey treated as $F_{3} ; F_{7}:$ skim milk was heated at 67 ${ }^{\circ} \mathrm{C}$ for $15-20 \mathrm{~s}$ before enzymatic coagulation; $F_{8}: F_{7}$ treated as $F_{2} ; F_{9}: F_{7}$ ultrafiltered at $50{ }^{\circ} \mathrm{C}$, concentrated 6 times; $F_{10}: F_{9}$ washed twice and concentrated 12 times; $F_{11}: F_{7}$ heated 60 min at $65^{\circ} \mathrm{C}$, ultrafiltered at $50^{\circ} \mathrm{C}$ and concentrated 6 times; $F_{12}: F_{11}$ washed twice before concentration.

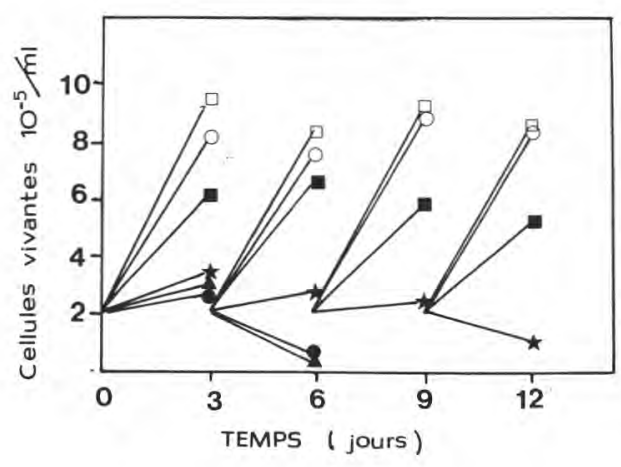

Fig 9. Comparaison de l'activité mitogénique de fractions de lactosérum additionnées ou non de SVF et du SVF. - $\square-$ SVF $10 \% ;-0$ - lactosérum S65 9\% + SVF 1\%; - - lactosérum S37 $9 \%+$ SVF $1 \% ;-\downarrow-$ SVF $1 \% ;-\longrightarrow$ lactosérum S65 10\%; - A- lactosérum S37 10\%.

Comparison between mitogenic activity of whey fractions with or without SVF and that of SVF. - - - SVF 10\%; - O- whey S65 9\% + SVF $1 \%$; - whey S37 9\% + SVF 1\%; - 丸 SVF 1\%; - whey S65 10\%; - - whey S37 10\%. 

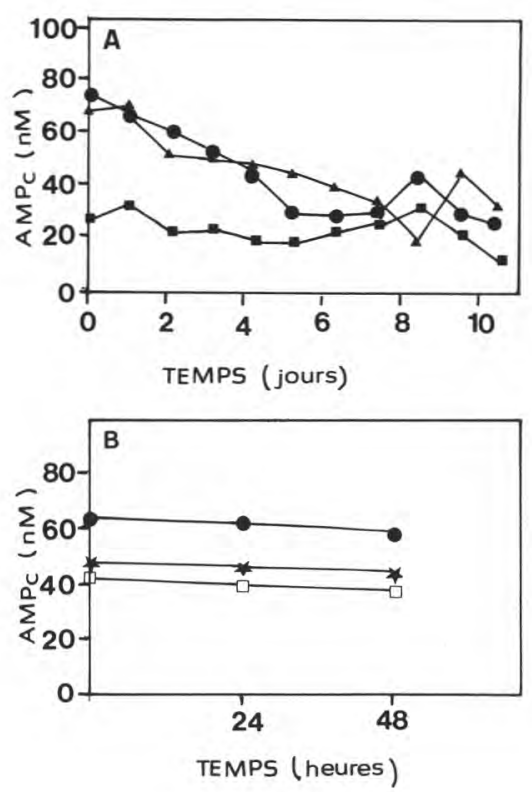

Fig 10. A: Consommation spécifique de l'AMPc contenu dans des fractions de lactosérum. lactosérum S65, $\mathbf{\Delta - \Delta}$ lactosérum S37 et dans du SVF - B: Contrôle montrant la stabilité à $37{ }^{\circ} \mathrm{C}$ de l'AMPc. $-\longrightarrow$ milieu de culture contenant $9 \%$ de lactosérum S65 + 1\% SVF, - - ¿ milieu conditionné prélevé au $4^{\mathrm{e}}$ jour de culture, $-\square-\square$ milieu conditionné prélevé au $4^{\mathrm{e}}$ jour de culture chauffé à $56^{\circ} \mathrm{C}$ pendant 30 min.

A: Specific consumption of cAMP contained in whey fraction; - whey $S 65, \boldsymbol{A}-\boldsymbol{\Lambda}$ whey S37, - SVF; B: Controls indicating CAMP stability at $37{ }^{\circ} \mathrm{C}$; - culture medium containing whey S65 9\% + SVF 1\%; - Ł conditioned medium at $d 4$ of culture, $-\square-\square$ conditioned medium at $d 4$ of culture and heated at $56{ }^{\circ} \mathrm{C}$ for $30 \mathrm{~min}$.

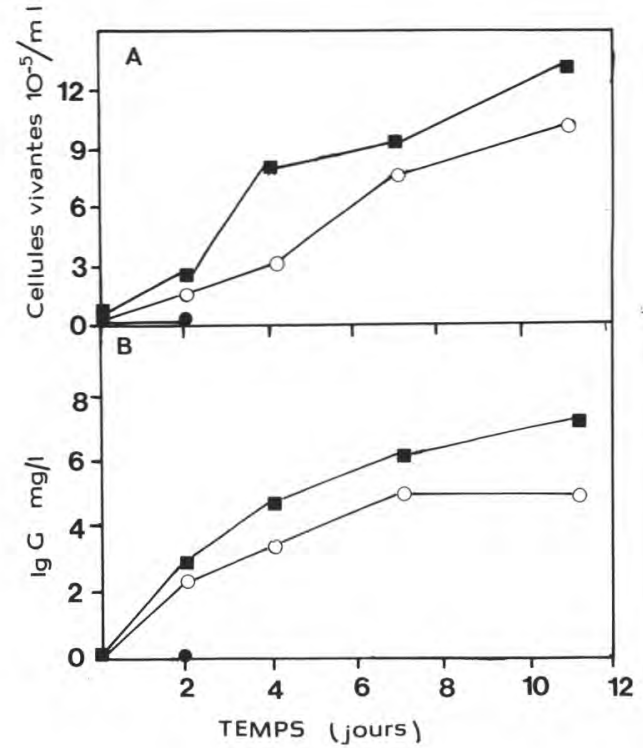

Fig 11. Exemple de reprise de la prolifération cellulaire $(A)$ et de la sécrétion d'immunoglobulines (B) d'hybridomes conservées 2 ans à $-80^{\circ} \mathrm{C}$. - cellules conservées en lactosérum et cultivées en SVF, -O-O cellules conservées et cultivées en lactosérum, - - cellules conservées et cultivées dans SVF.

Cell proliferation $(A)$ and $\lg$ secretion $(B)$ of frozen cells at $-80^{\circ} \mathrm{C}$; - cells frozen with whey and cultured with SVF; - O-O cells frozen and cultured with whey, - cells frozen and cultured in SVF.

Fig 12. Microscopie électronique des cellules conservées 2 ans à $-80^{\circ} \mathrm{C}$ en lactosérum ou en SVF. Electron microscopic view of frozen cells at $-80^{\circ} \mathrm{C}$ in whey $\boldsymbol{A}$ or in FCS B. 

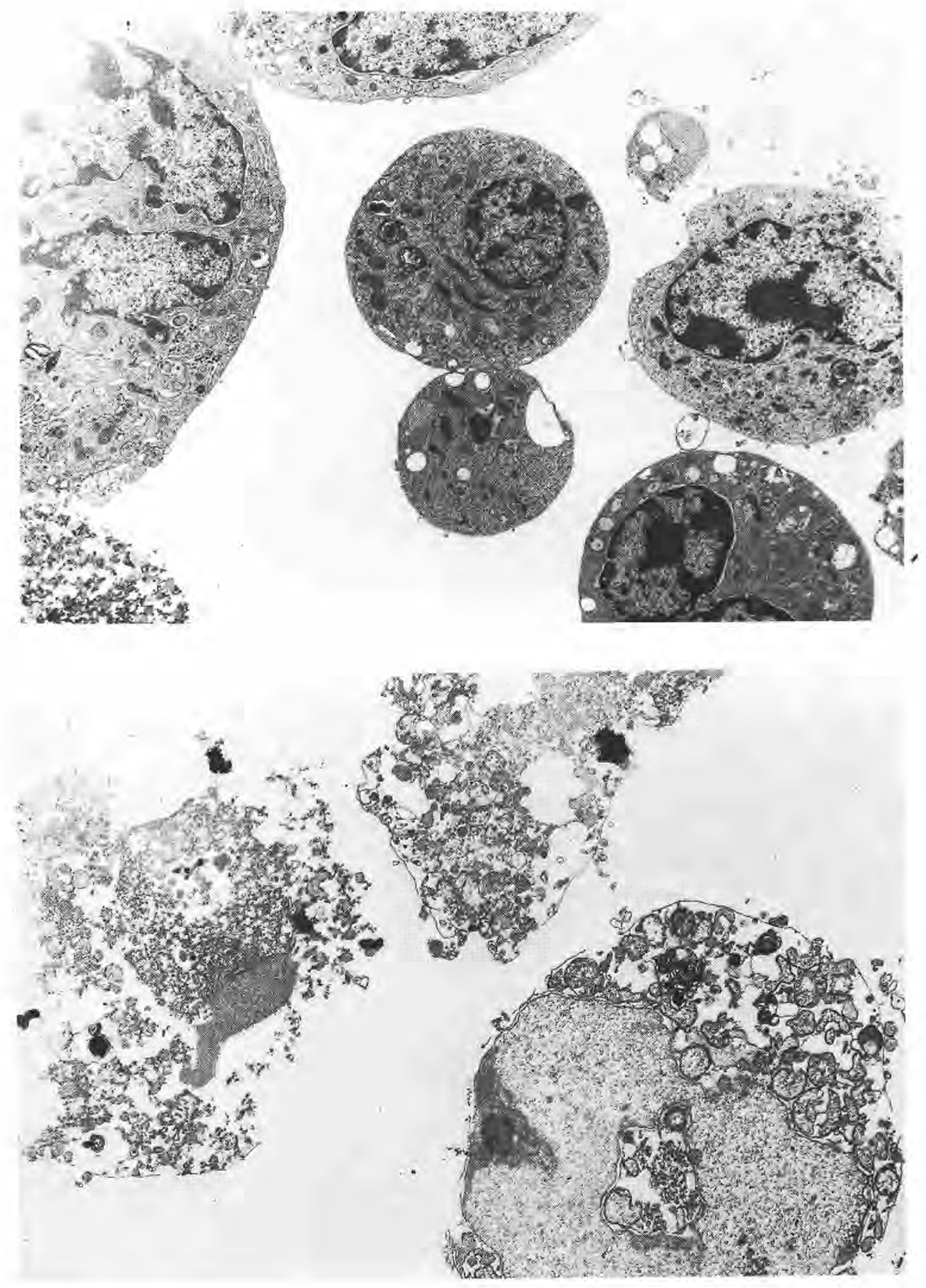


\section{RÉFÉRENCES}

Damerdji O, Derouiche AF, Legrand C, Capiaumont J, Bour JM, Maugras M, Belleville F, Nabet P, Paquet D, Linden G (1988) Utilization of whey fractions as a substitute for fetal calf serum in culture media. Biotechnol Tech 2, 253-258

Derouiche AF, Bour JM, Legrand C, Capiaumont $J$, Belleville $F$, Linden $G$, Nabet $P$ (1989) Improved long-term storage of hybridoma at $-80{ }^{\circ} \mathrm{C}$ using a bovine milk derivative. J Immunol Methods 125, 13-18

Derouiche AF, Legrand C, Bour JM, Capiaumont J, Gelot MA, Dousset B, Belleville F,
Nabet P, Linden G (1990) Biochemical aspects of a whey fraction capable of promoting hybridoma proliferation. Comparison with fetal calf serum. Lait 70, 313-324

Juskevich JC, Guyer CG (1990) Bovine growth hormone : human food safety evaluation. Science 249, 875-884

Klagsburn M (1978) Human milk stimulates DNA synthesis and cellular proliferation in cultured fibroblasts. Proc Natl Acad Sci USA 75, 5057-5061

Read LC (1989) Milk growth factors. In: fetal and Neonatal growth (Cockburn F , ed), J Wiley, New York 